\title{
Erratum:
}

\section{Retraction Note To: The fIhDC gene affects motility and biofilm formation in Yersinia pseudotuberculosis}

WANG Yao, et al. The $f l h D C$ gene affects motility and biofilm formation in Yersinia pseudotuberculosis. Sci China Ser C-Life Sci, 2007, 50(6): 814-821

\section{Editorial Statement Science in China Press}

According to our policy on copyright transfer, we hereby announce that the paper of "The $f l h D C$ gene affects motility and biofilm formation in Yersinia pseudotuberculosis", authored by WANG Yao et al., be retracted from Volume 50, No. 6, December 2007 of Sci China Ser C-Life Sci on pages 814-821. In fact, the majority of the work was carried out in Prof. Paul Williams' laboratory at the Institute of Infection, Immunity and Inflammation, Centre for Biomolecular Sciences, University of Nottingham, UK, and the paper was submitted without his knowledge or permission. In addition, the work was part of a manuscript which was being revised for a different journal.

It is our expectation that all co-authors can attest the submitting situation before signing their names at the time of submitting it to Sci China Ser C-Life Sci. Following common practices of many international journals, all the co-authors of the paper shall share the associated responsibility and be disciplined according to the established rules and procedures of Sci China Ser C-Life Sci when any misconduct can be determined. Therefore, we would like to advise all the authors to take the above issue seriously when signing their names. 